\title{
DOING IT RIGHT - CRITICAL SUCCESS FACTORS FOR DESIGN THINKING IMPLEMENTATION
}

\author{
De Paula, Danielly (1,2); Dobrigkeit, Franziska (2); Cormican, Kathryn (1) \\ 1: National University of Ireland - Galway; 2: Hasso-Plattner-Institut
}

\begin{abstract}
Proficiency in design thinking (DT) can contribute to the success of many companies. Successful implementation of DT can be achieved by identifying its Critical Success Factors (CSFs). Critical success factors are items or actions that should be present in a particular project or situation in order to be successful. However, to date, there has not been any formal study on synthesizing the critical success factors for a successful DT implementation based on existing research. In light of this, the aim of this paper is to develop a conceptual framework that proposes factors that may play a role in influencing the success of the DT implementation. Based on best practices and protocols from thematic analysis, we analyzed and synthesized extant literature in order to recognize research topics from the selected papers and categorize them into specific themes to build a framework. This study significantly contributes to the body of knowledge related to DT by offering the first attempt to identify CSFs for DT implementation, which can allow companies to take required precautions to elude failures or problematic areas and be able to increase the success rate of implementing DT
\end{abstract}

Keywords: Design Thinking, Critical success factors, Innovation, Design management, Decision making

Contact:

De Paula, Danielly

Hasso Plattner Institute

Enterprise Platform and Integration Concepts

Germany

danielly.depaula@hpi.de

Cite this article: De Paula, D., Dobrigkeit, F., Cormican, K. (2019) 'Doing it Right - Critical Success Factors for Design Thinking Implementation', in Proceedings of the 22nd International Conference on Engineering Design (ICED19), Delft, The Netherlands, 5-8 August 2019. DOI:10.1017/dsi.2019.392 


\section{INTRODUCTION}

Design thinking (DT) is a term being used today to define a way of thinking that produces transformative innovation (Gloppen, 2009). Successful implementation of DT can be achieved by identifying its Critical Success Factors (CSFs). In general, the literature refers to critical success factors as items or actions that should be present in a particular project or situation in order to be successful (Eybers and Giannakopolous, 2015). For this study, CSFs are those factors crucial to the implementation of DT. The identification of such factors must be considered if companies want to successfully implement design thinking. However, to date, there has not been any formal study on synthesizing the critical success factors for a successful DT implementation based on existing research.

Most researchers prone to propose enhancements to the methods (Seidel and Fixson, 2013), tools (Holloway, 2009) and spaces (Carlgren et al., 2014) rather than investigating general conditions to facilitate the creation of a DT culture. Additionally, even though there are some studies on how to facilitate a DT implementation (Liedtka, 2015) and how DT contributes to organizations (Carlgren et al., 2014), they are scattered and lack a comprehensive synthesis to allow researchers to understand the underlying factors for an effective implementation of DT. In light of this, the aim of this paper is to develop a conceptual framework that proposes factors that may play a role in influencing the success of the DT implementation.

This exploratory study was conducted following a two-phased approach. First, current academic literature was investigated in order to identify CSFs from previous empirical studies. Based on that, best practices and protocols from thematic analysis (Thorpe et al., 2005) were used to not only synthesise and understand the extant literature but also recognize research topics from the selected papers and categorize them into specific themes in order to build a framework.

This research is a first step to identify CSFs for DT implementation. By identifying the CSFs, companies can take required precautions to elude failures or problematic areas and be able to increase the success rate of implementing DT. From an academic perspective, this study will significantly contribute to the body of knowledge related to DT by (i) offering the first attempt to identify CSFs for DT implementation and (ii) directing research efforts to further analyze the benefits and barriers of design thinking.

\section{LITERATURE REVIEW}

Many authors suggest that DT can provide significant value to innovation and management (Liedtka, 2015; Rosensweig, 2011). DT is emerging in the management literature as a concept that promises innovation through a more user-centred approach which suggests that companies can learn from the way designers think and work (Brown, 2008; Martin, 2009). As a result, it has been introduced in many different organizational settings, such as, small and medium-sized enterprises (SMEs) (Acklin, 2010) and large organizations (Chang et al., 2013). Recently, in order to encourage innovation and economic growth, researchers are investigating how to use DT as an organizational resource to reinvent the entire company's design strategy (Cipolla and Moura, 2011).

Prior research has demonstrated that DT offers a potent way to create breakthrough products (Brown, 2008; Perks et al., 2005). Similarly, Brown (2009) suggests that DT facilitates product appropriateness and adoption, which can lead to customer satisfaction. In this way, researchers suggest that DT can have a significant impact across the entire NPD process. For instance, D'Ippolito (2014) suggests that having multiple professionals who are equipped with DT skills during the design process can increase collaboration, lead to product differentiation and consequently, contribute to firms' competitiveness. Seidel and Fixson (2013) claim that the increasingly widespread use of DT leads to the existence of multidisciplinary teams during the concept generation phase of the design process which brings positive effects - such as increased team reflexitivity. From a more general perspective, Carlgren et al. (2014) found that incorporating DT into the NPD process can result in significant cost savings as DT is lauded to reduce redesign work and shorten lead time to development. Liedtka (2015) claims that DT improves design outcomes because its tools and attitudes address and mitigate the cognitive biases that strongly impact any creative process and represent flaws that can result in failures. Taking advantage of DT can help business leaders make their intentions real — by clearly defining goals, deeply understanding customers, and getting their internal teams aligned to deliver results (Clark and Smith, 2010).

DT is an established way to bring value to some parts of business, yet it remains a well-kept secret from many who could use it most (Clark and Smith, 2010). One possible explanation for that is that the 
concept of design thinking is broad (Cooper et al., 2009), and the term is considered as confusing; there are debates over what exactly is meant by it, and how, if at all, it differs from e.g. creativity, innovation or systems thinking (Kimbell, 2009). To further understand these issues, it is necessary to understand how DT manifests itself in organizations and what are the critical factors that can help companies to successfully implement DT.

\subsection{Benefits and challenges of design thinking}

Proficiency in DT can contribute to the success of many companies. Design thinking addresses complex problems in uncertain contexts and mobilizes tools and attitudes to that end (Ben Mahmoud-Jouini et al., 2016). A central proposition of DT is that it can be helpful for a range of business challenges that exceed the traditional focus of industrial design and should be pursued by non-designers as well as designers (Brown and Katz, 2011). Recent developments in design thinking claim that it needs to move "upstream" where strategic decisions are made (Brown, 2009). According to Carlgren et al. (2016b), there is a growing interest for DT among managers. The authors suggest that management should be encouraged to connect with users because it can make them reflect on the values that were guiding development and innovation in the organization. This entails a need for management to follow DT initiatives more closely and to develop recruitment methods, skills development and evaluation methods in parallel with the initiatives. In particular, DT is driven by intelligence that embraces innovation and gives companies the freedom to explore multiple ways to solve problems and discover the option that best delivers competitive advantage (Clark and Smith, 2010). Recognizing patterns (Brown, 2009; Carr et al., 2010; Sato et al., 2010) and relationships in the broad number of diverse variables, including conflicting, ambiguous, or paradoxical data is central to DT. One of the foundations of design thinking is said to bring competing constraints into a harmonious balance (Brown, 2009). Most authors see this as being achieved through integrative thinking, which is about identifying salient aspects (Brown, 2008; Dunne and Martin, 2006) of problems and being able to face two (or more) opposing ideas or models and instead of choosing one versus the other, to generate a creative resolution of the tension in the form of a better model, which contains elements of each model. (Brown, 2008; Fraser, 2009; Martin, 2010). Defining the problem to solve and thereby articulating the project's strategy is indeed a critical task for DT (Ben Mahmoud-Jouini et al., 2016). In this way, the core of DT remains the ability to conceive, plan, and present ideas about products (Gloppen, 2009). Furthermore, it is opposed to linear and analytical problem-solving approaches that are unlikely to resolve "wicked" problems, that lack both definitive formulations and solutions and are characterized by high uncertainty and ambiguity (Ben Mahmoud-Jouini et al., 2016). Overall, the challenges of using design thinking include misfit with existing processes and structures; resulting ideas and concepts are difficult to implement; value of DT is difficult to prove; DT principles/mindsets clash with organizational culture; existing power dynamics are threatened; skills are hard to acquire; and communication style is different (Carlgren et al., 2016a). Similarly, Carlgren et al. (2016b) summarize design thinking principles as user focus, problem framing, visualization, experimentation and diversity. By understanding the benefits and challenges associated with DT, researchers can investigate what different design thinking strategies for specific scenarios.

\section{RESEARCH METHOD}

In order to contribute to peer reviewed academic literature on CSF for DT implementation, this exploratory study followed a two-phase approach.

The first phase aimed at providing a theoretical basis for conducting the study and for the development of the framework. In this phase, the research question was defined in order to delimitate our scope and position our work related to other researchers. The following research question guided this phase: What are the critical success factors for a successful DT implementation?

In order to answer the research question, a literature review was carried out on the main topics related to DT implementation in companies. The search process adapted is similar to Eybers and Giannakopolous (2015). An electronic search was conducted by topic ("Design Thinking") across established peer reviewed academic journals and databases of conference proceedings. In addition, the success factors and barriers for DT adoption and the different levels of DT implementation were investigated. As a result of this phase, we identified 20 CSFs. 
By drawing on principles of thematic classification (Thorpe et al., 2005), the list of 20 CSFs was broken down descriptively and thematically to derive dimensions that categorize the list. To perform a thorough analysis of the CSFs, tables were used to compare factors and provide a brief description of them. By doing that, it was possible to recognize patterns and categorise them into dimensions to build the framework. By following a rigorous synthesis approach (Chatterjee and Sahasranamam, 2018) to review selected studies and reveal themes, we developed a framework and identified future research area. In the thematic analysis, the abstracts were coded and further analysed to derive themes. After a rigorous research process, the framework was created based on 20 CSFs organized within four core dimensions: Strategy, Process, Competence and Culture.

\section{FINDINGS}

A substantial number of CSFs were identified when the material from the academic search process was evaluated. Related CSFs were grouped together into four categories namely Strategy, Process, Competence and Culture (Figure 1). Table 1 contains the list of the 20 CSFs identified.

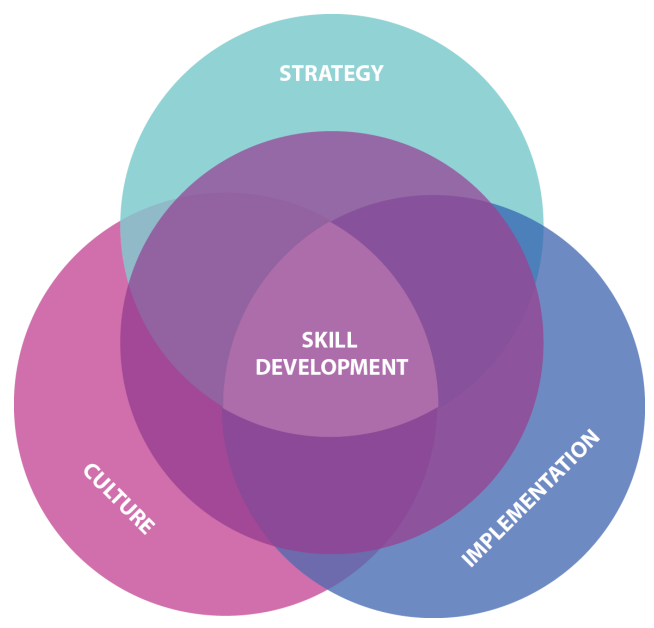

Figure 1. Dimensions of the CSF framework

\subsection{Strategy}

The first category to emerge from the literature review analysis is strategy. This category aims to identify what practices can support companies when developing a design thinking strategy.

Many researchers discuss management support to be critical to the success of DT implementation (Liedtka et al., 2013; Martin, 2009). Since DT challenges not only organization of work but also power structures, managers that want to truly engage in DT need to firmly communicate their support and encourage their employees to engage in its implementation (Carlgren et al., 2016b). In this way, the need to improve the link between DT and strategy is highlighted by recent research. Carlgren et al. (2016b) note that ensuring management support is imperative if teams want to have the necessary resources to perform DT-related activities. Similarly, Brown (2008) states that it is important to bring DT's principles, methods and tools to management and business. DT can provide project management with new perspectives for addressing innovation challenges. Most importantly, in order to effective inject DT into organizations; it is imperative to help leaders of organizations understand and appreciate the value and contribution of designers, design, and DT (Gloppen, 2009).

Another key factor of DT implementation is the need to provide professionals with tools to engage in robust DT. According to Rauth et al. (2014), the implementation of DT usually requires a change in the organization culture, the creation of new job positions and new physical spaces - which means cost for organizations. In this way, having access to funding can facilitate the design thinking initiatives. Additionally, one of the barriers in the adoption of design thinking is the lack of traceability. In particular, it is difficult for companies to link the product acceptance to the design thinking implementation (Carlgren et al., 2016a). In this way, one of the core elements for design thinking survival is to identify how it can be measured. 
Table 1. Overview of the identified critical success factors

\begin{tabular}{|c|c|c|}
\hline Dimensions & Factors & Source \\
\hline \multirow[t]{4}{*}{ Strategy } & Secure management support & $\begin{array}{l}\text { Carlgren et al. (2016A), Holloway (2009), } \\
\text { Rosensweig (2011), Hassi et al. (2011) }\end{array}$ \\
\hline & $\begin{array}{l}\text { Having fundamental } \\
\text { guidelines for design thinking }\end{array}$ & $\begin{array}{l}\text { Rosensweig (2011); Kimbell (2009); Hassi } \\
\text { et al (2011) }\end{array}$ \\
\hline & $\begin{array}{l}\text { Ensure funding for design } \\
\text { thinking initiatives }\end{array}$ & Carlgren et al. (2016A), Brown (2008); \\
\hline & Having clear metrics & Carlgren et al. (2016), Liedtka (2011) \\
\hline \multirow[t]{5}{*}{ Culture } & Diversity orientation & $\begin{array}{l}\text { Holloway (2009), Rosensweig (2011), Hassi } \\
\text { et al. (2011) }\end{array}$ \\
\hline & Foster empathy & $\begin{array}{l}\text { Brown (2008), Kimbell (2009), Liedtka (2011), } \\
\text { Lockwood (2009) }\end{array}$ \\
\hline & $\begin{array}{l}\text { Ability to handle ambiguitious } \\
\text { situations }\end{array}$ & $\begin{array}{l}\text { Dunne \& Martin (2006), Gloppen (2009), Sato } \\
\text { et al (2010) }\end{array}$ \\
\hline & $\begin{array}{l}\text { Ability to handle complexity } \\
\text { and uncertainty }\end{array}$ & $\begin{array}{l}\text { Liedtka (2011), Bolland \& Collopy (2004), } \\
\text { Cooper et al. (2009), Dew (2007) }\end{array}$ \\
\hline & $\begin{array}{l}\text { Establish collaboration and } \\
\text { cross-functional teams }\end{array}$ & $\begin{array}{l}\text { Dunne \& Martin (2006), Gloppen (2009), Sato } \\
\text { et al. (2010) }\end{array}$ \\
\hline \multirow[t]{6}{*}{ Implementation } & Provide necessary material & Micheli et al. (2012), Calrgren et al. (2014) \\
\hline & Innovation spaces & Carlgren et al. (2014), Brown (2008) \\
\hline & $\begin{array}{l}\text { Establish flexible and } \\
\text { responsive processes }\end{array}$ & $\begin{array}{l}\text { Holloway (2009), Rosensweig (2011) Brenner } \\
\text { et al (2016) }\end{array}$ \\
\hline & $\begin{array}{l}\text { Integrate DT into NPD and } \\
\text { related processes }\end{array}$ & Micheli et al. (2012), Rosensweig (2011) \\
\hline & $\begin{array}{l}\text { Apply lessons learned from } \\
\text { past projects }\end{array}$ & $\begin{array}{l}\text { Wölbling et al. (2012), Carlgren et al. (2016), } \\
\text { Brenner et al. (2016) }\end{array}$ \\
\hline & Access to the user & $\begin{array}{l}\text { Brown (2008); Holloway (2009); Ward } \\
\text { et al (2009) }\end{array}$ \\
\hline \multirow[t]{5}{*}{ Competences } & Provide training on DT & $\begin{array}{l}\text { Micheli et al. (2012), Carlgren et al. (2016), } \\
\text { Rosensweig (2011) }\end{array}$ \\
\hline & $\begin{array}{l}\text { Collaborative initiative with } \\
\text { key partners }\end{array}$ & Micheli et al. (2012), Rosensweig (2011) \\
\hline & Create DT awareness & $\begin{array}{l}\text { Dunne \& Martin (2006), Sato et al. (2010), } \\
\text { Carlgren et al. (2014) }\end{array}$ \\
\hline & Enable the optimal team skills & $\begin{array}{l}\text { Carlgren et al. (2016), Brown (2008), Seidel et al. } \\
(2013)\end{array}$ \\
\hline & $\begin{array}{l}\text { Include DT principles into } \\
\text { everyday work }\end{array}$ & $\begin{array}{l}\text { Carlgren et al. (2016), Brown (2008), Liedtka } \\
\text { (2011) }\end{array}$ \\
\hline
\end{tabular}

\subsection{Culture}

Under the dimension culture, we summarized CSFs that are necessary in order to foster a DT culture inside a company.

Collaboration and team diversity are also suggested as being critical factors to foster a DT culture (Boland, 2004; Brown, 2008). Building community and working across professional borders is an important residue of DT (Clark and Smith, 2010). The focus on collaboration through crossfunctional teams associated with DT is seen as enhancing collective creative problem solving by bringing to conversations diverse points of view (Carlgren et al., 2016b). By using interdisciplinary teams, DT incorporates diversity and leverages different paradigms and tool sets from each profession to analyze, synthesize, and generate insights and new ideas. The interdisciplinary nature of DT also ensures that innovations are naturally balanced between the technical, business, and human dimensions (Holloway, 2009). A collaborative work style is seen as important in tackling complex and "wicked" problems through gaining knowledge from many fields and disciplines (Gloppen, 2009), promoting diverse perspectives and merging them in a meaningful and novel way (Dunne and Martin, 2006). Some 
authors also emphasize that thinking is not something done exclusively inside one's head, but is often accomplished in interaction with other people (Boland, 2004), using expressions such as collaborative integrative thinking (Dunne and Martin, 2006).

Additionally, authors were extremely consistent in emphasizing developing empathy towards and understanding of the customer/users (Clark and Smith, 2010; Dunne and Martin, 2006; Holloway, 2009; Lockwood, 2009). It has been argued that in order to perform DT-related activities it is necessary to foster a culture that promotes empathy towards the user and co-workers (Brown, 2009). Another core factor of design is that it requires a high tolerance for ambiguity and uncertainty. Liedtka (2015) states that contexts in which there are high uncertainties and ambiguity can benefit from an experimental approach that explores multiple solutions. Ambiguity is accepted as a natural part of the process (Rylander, 2009) as the inquiry is rather emerging than deterministic (Cooper et al., 2009). Therefore a key feature of the design thinkers' mentality is being comfortable with the ambiguous (Drews, 2009), and maintaining the ability to work in the face of ambiguity. Indeed, managers and especially executives have to deal with decisions under circumstances of uncertainty and ambiguity. They address messy and ill-structured situations, therefore, they can benefit from DT as a way to approach indeterminate organizational problems (Martin, 2009).

\subsection{Implementation}

This dimension combines CSFs that support employees when implementing design thinking.

A core element to make DT happen is to make the necessary material available for employees to use. Using artifacts (e.g. post-its, lego, etc) to express ideas through prototype can be used for communication, alignment, and living requirement specifications to provide clarity and transparency during the production of the solution (Holloway, 2009). By using material to prototype, teams can validate the solution with end-users and project stakeholders. In this way, the DT approach encourages teams to create "project war rooms" and to work visually using pictures, diagrams, sketches, video clips, photographs, and artifacts collected from their research to create immersive work environments that allow the team to gain deeper, more intuitive empathy and understanding of their users' needs.

Another core element of DT is to learn how to deploy appropriate methods in order to be flexible and responsive to different project's needs (Rosensweig, 2011). As mentioned before, design thinking can manifest itself in different ways. In this way, teams should able to able to have a flexible mindset in order to identify the best strategy for each project. Authors suggest that arranging specific physical space for innovation work can enable flexibility, spontaneous team working and visualization (Carlgren et al., 2014).

Contemporary scholarship has suggested that integrating DT into the new product development is essential for its successful application (Ben Mahmoud-Jouini et al., 2016). Best (2006) notes that integrating the DT process into the other product development strategies by which an organization plans to achieve its goals will improve its competitive position.

However, there are different ways of integrating DT into the product development process. In order to understand the potential that DT may have for product development, it is necessary to understand all the different ways that DT manifests itself. Authors suggest that the DT application can have three different natures: as a mindset, as a process or as toolbox (Wölbling et al., 2012; Brenner et al., 2016). As a mindset, DT is characterized by several key principles, such as a strong orientation to both obvious and hidden needs of customers and users, and prototyping (Brenner et al., 2016). By following this line, authors also suggest that applying the principles alone - without structure - is too demanding for novices (Brenner et al., 2016). In this way, in some cases it is necessary to follow a structured process in order for novices to understand what DT is and how it can contribute to the product development process. Additionally, there are different design collections of tools, both aimed at practitioners (Stickdorn et al., 2011) and academics (Hassi and Laakso, 2011). Deployment of appropriate methods is one of the core success factors of DT projects (Brenner et al., 2016), therefore it is imperative that teams fully understand how to apply them. Therefore, it is essential that teams learn from past projects a comprehensive way of integrating DT into the product development process in order to address the project's goals.

One of the most prominently emphasized elements of DT is its inherently and thoroughly humancentered approach - "putting people first" (Brown, 2008; Porcini, 2009; Ward et al., 2009). DT helps 
to more-deeply understand customers' wants and needs (spoken and unspoken) and link them to the capabilities of globally integrated enterprises (Clark and Smith, 2010)

\subsection{Competence}

Employees and their competences are critical components for companies and critical resources for their innovation capability (Carlgren et al., 2014). Brown (2009) calls for DT to be dispersed throughout the organization and beyond the sole designers. Design professionals could redefine their leadership by being catalysts to help other parts of the organization use and embrace DT (Clark and Smith, 2010). According to Liedtka et al. (2013), all professional roles should learn some things from the way designers think. Authors discuss many different ways that DT can contribute to organizations. Scholars argue that DT can enable the expansion of an organization's innovation capabilities because of its ability to include non-designers in the design process (Rosensweig, 2011). Design thinkers are said to pose questions and explore constraints in creative ways that proceed in entirely new directions (Brown, 2008). In addition, important skills in DT include imagination, creativity, innovation, and value creation (Gloppen, 2009). Therefore, it is fundamental to promote awareness of DT implementation among all functions in the company. In order to spread DT, some companies make investments in different strategies such as providing workshops, mentoring and training. This is in line with Seidel and Fixson (2013) who claim that managers promoting DT in their organizations should ensure that teams using design methods receive additional guidance.

Securing collaborative support from key partners can a be a way to improve employees' design thinking competence Rosensweig (2011). In this way, companies could promote projects in partnership with universities and/or research institutes. Another core element of design thinking is the ability to combine the different skills through multidisciplinary teams in order to bring different perspectives to project development Seidel and Fixson (2013).

\subsection{Summary}

By reflecting on the identified CFS, it is possible to notice that the success factors identified here have the potential to support some of the DT principles and/or address pressing challenges. As discussed in section 2, Carlgren et al. (2016b) summarize design thinking principles as: (P1) user focus, (P2) problem framing, (P3) visualization, (P4) experimentation and (P5) diversity. As also discussed in section 2, the challenges of implementing DT are $(\mathrm{C} 1)$ misfit with existing processes and structures, $(\mathrm{C} 2)$ resulting ideas and concepts are difficult to implement, (C3) value of DT is difficult to prove, (C4) DT principles/mindsets clash with organizational culture, (C5) existing power dynamics are threatened, (C6) skills are hard to acquire and (C7) communication style is different. Table 2 provides an overview of CSFs and which principles (Carlgren et al., 2016b) they support or which challenges (Carlgren et al., 2016a) they help to address.

For instance, integrating DT into the NPD process and ensuring that company processes are flexible and responsive to change addresses misfits of DT with existing processes. Similarly, securing management support helps to prepare teams for changes in power dynamics. The table shows that more success factors that support the DT principles of user focus (P1) and visualization (P3) should be identified. Similarly, more success factors should be identified that can address the challenge of existing power dynamics are threatened (C5). Finally, although the CSFs were grouped into four different dimensions, they are not mutually exclusives to one dimension. For instance, some factors from Implementation could also belong to the dimension Competence and vice versa. In this way, the items can overlap. Furthermore, the factors are not independent from one another. For instance, "having clear metrics" can shape how employees handle ambiguity, complexity and uncertainty and thus might hinder or support the according CSF from the culture dimension. Similarly, it is necessary to ensure funding for DT initiatives as seen in the Strategy dimension, in order to provide training, spaces and materials as requested by the CSFs in the Implementation dimension.

\section{IMPLICATIONS AND CONCLUSION}

This study sets out to use literature review and thematic classification to identify critical success factors for design thinking implementation. This research is the first step to identify and afford insight into the CSFs for DT implementation. First of all, to the best of our knowledge there is no single accepted list of 
Table 2. overview of critical success factors and the $d t$ principles they support and the challenges they addresses

\begin{tabular}{|l|l|l|l|l|l|l|l|l|l|l|l|l|}
\hline$C S F$ & $P 1$ & $P 2$ & $P 3$ & $P 4$ & $P 5$ & $C 1$ & $C 2$ & $C 3$ & $C 4$ & $C 5$ & $C 6$ & $C 7$ \\
\hline 1.Secure management support & & & & & $\mathrm{X}$ & & $\mathrm{X}$ & & & $\mathrm{X}$ & & \\
\hline $\begin{array}{l}\text { 2.Having fundamental guide- } \\
\text { lines for design thinking }\end{array}$ & & $\mathrm{X}$ & & & & $\mathrm{X}$ & & & $\mathrm{X}$ & & & \\
\hline $\begin{array}{l}\text { 3.Ensure funding for design } \\
\text { thinking initiatives }\end{array}$ & & $\mathrm{X}$ & & & & $\mathrm{X}$ & & & & $\mathrm{X}$ & \\
\hline 4.Having clear metrics & & & $\mathrm{X}$ & & & $\mathrm{X}$ & & $\mathrm{X}$ & & & & \\
\hline 5.Diversity orientation & & & & & $\mathrm{X}$ & $\mathrm{X}$ & & & & & & $\mathrm{X}$ \\
\hline 6.Foster empathy & $\mathrm{X}$ & & & & & & & & & $\mathrm{X}$ & & $\mathrm{X}$ \\
\hline $\begin{array}{l}\text { 7. Ability to handle ambiguous } \\
\text { situations }\end{array}$ & & $\mathrm{X}$ & & & & & $\mathrm{X}$ & & $\mathrm{X}$ & & & \\
\hline $\begin{array}{l}\text { 8.Ability to handle complexity } \\
\text { and uncertainty }\end{array}$ & & $\mathrm{X}$ & & & & & $\mathrm{X}$ & & $\mathrm{X}$ & & & \\
\hline $\begin{array}{l}\text { 9.Enable collaboration and } \\
\text { cross-functional teams }\end{array}$ & & & & & $\mathrm{X}$ & $\mathrm{X}$ & & & $\mathrm{X}$ & & & \\
\hline 10.Provide necessary material & & & & $\mathrm{X}$ & & & & & $\mathrm{X}$ & & & $\mathrm{X}$ \\
\hline 11.Establish innovation spaces & & & & $\mathrm{X}$ & & & $\mathrm{X}$ & & $\mathrm{X}$ & & & \\
\hline $\begin{array}{l}\text { 12.Establish flexible and } \\
\text { responsive processes }\end{array}$ & & & & $\mathrm{X}$ & & $\mathrm{X}$ & & $\mathrm{X}$ & & & & \\
\hline $\begin{array}{l}\text { 13.Integrate DT into the NPD } \\
\text { and related process }\end{array}$ & & & & $\mathrm{X}$ & & $\mathrm{X}$ & & & $\mathrm{X}$ & & & \\
\hline $\begin{array}{l}\text { 14.Apply lessons learned from } \\
\text { past projects }\end{array}$ & & & $\mathrm{X}$ & & & & $\mathrm{X}$ & & & $\mathrm{X}$ & \\
\hline 15.Access to the user & $\mathrm{X}$ & & & & & & & $\mathrm{X}$ & & & & $\mathrm{X}$ \\
\hline 16.Provide training on DT & & & & $\mathrm{X}$ & & & & & & $\mathrm{X}$ & $\mathrm{X}$ & \\
\hline $\begin{array}{l}\text { 17.Collaborative initiatives with } \\
\text { key partners }\end{array}$ & & & & $\mathrm{X}$ & & $\mathrm{X}$ & & & & $\mathrm{X}$ & \\
\hline 18.Create DT awareness & & & & $\mathrm{X}$ & $\mathrm{X}$ & & & $\mathrm{X}$ & & & \\
\hline 19.Optimal team skills & & & & & $\mathrm{X}$ & & & & $\mathrm{X}$ & $\mathrm{X}$ & & \\
\hline $\begin{array}{l}\text { 20.Include DT principles into } \\
\text { everyday work }\end{array}$ & $\mathrm{X}$ & & & & & & & $\mathrm{X}$ & & $\mathrm{X}$ & \\
\hline
\end{tabular}

critical success factors for design thinking. In this way, the aim of this research was to propose factors that may play a role in influencing the success of the DT implementation. By identifying the CSFs, companies can take required precautions to elude failures or problematic areas and be able to increase the success rate of implementing DT.

They key contribution of this research is to have an initial list of CSFs based on what researchers have found to be core elements to the design thinking implementation. The study revealed that one of the most important topics of discussion among scholars is to understand how to successfully implement DT in business organizations. From this review, we identified 4 key dimensions and 20 critical success factors that can provide both scholars and practitioners with a more holistic view of DT success. However, this study was not without limitations, future research will need to empirically validate the findings. In this way, this study was only the first step towards understanding what critical factors play a role when implementing DT. As future work, the next step of this research is to validate the list with the industry. In particular, the CSFs will be organized into a survey and applied to DT practitioners. The goal of the survey will be to ensure the items are reliable and also to measure the extent of importance and implementation of each item. The overall goal is to rank the factors and determine which ones are indeed critical to companies. The study therefore concludes with a initial list of CSFs for DT implementation based on the existing literature. 


\section{ACKNOWLEDGMENTS}

This research was undertaken with support from Conselho Nacional de Desenvolvimento Científico e Tecnológico (CNPQ) - Brazil and the Hasso Plattner Design Thinking Research Program.

\section{REFERENCES}

Acklin, C. (2010), “Design-Driven Innovation Process Model: Design and the Innovation Process", Design Management Journal, Vol. 5 No. 1, pp. 50-60.

Ben Mahmoud-Jouini, S., Midler, C. and Silberzahn, P. (2016), "Contributions of Design Thinking to Project Management in an Innovation Context", Project Management Journal, Vol. 47 No. 2, pp. 144-156.

Best, K. (2006), Design Management: Managing Design Strategy, Process and Implementation, AVA publishing. Boland, R.J. and Collopy, F. (2004), Design matters for management (pp. 3-18). na.

Brenner, W., Uebernickel, F. and Abrell, T. (2016), "Design Thinking as Mindset, Process, and Toolbox", in Brenner, W. and Uebernickel, F., eds., Design Thinking for Innovation, Springer International Publishing.

Brown, T. (2008), "Design thinking”, Harvard Business Review, Vol. 86 No. 6, p. 84.

Brown, T. (2009), "Change by Design: How Design Thinking Transforms Organizations and Inspires Innovation", HarperBusiness.

Brown, T. and Katz, B. (2011), "Change by design”, Journal of Product Innovation Management, Vol. 28 No. 3, pp. 381-383.

Carlgren, L., Elmquist, M. and Rauth, I. (2014), "Design Thinking: Exploring Values and Effects from an Innovation Capability Perspective", The Design Journal, Vol. 17 No. 3, pp. 403-423.

Carlgren, L., Elmquist, M. and Rauth, I. (2016A), “The Challenges of Using Design Thinking in Industry Experiences from Five Large Firms: the challenges of using DT in industry creativity and innovation management", Creativity and Innovation Management, Vol. 25 No. 3, pp. 344-362.

Carlgren, L., Rauth, I. and Elmquist, M. (2016B), "Framing design thinking: The concept in idea and enactment". Creativity and Innovation Management, Vol. 25 No. 1, pp. 38-57.

Carr, S.D., Halliday, A., King, A.C., Liedtka, J. and Lockwood, T. (2010), "The Influence of Design Thinking in Business: Some Preliminary Observations", Design Management Review, p. 21.

Chang, Y., Kim, J. and Joo, J. (2013), “An Exploratory Study on the Evolution of Design Thinking: Comparison of Apple and Samsung", Design Management Journal, Vol. 8 No. 1, pp. 22-34.

Chatterjee, D. and Sahasranamam, S. (2018), "Technological innovation research in China and India: A bibliometric analysis for the period 1991-2015”, Management and Organization Review, Vol. 14 No. 1, pp. 179-221.

Cipolla, C. and Moura, H. (2011), "Social Innovation in Brazil Through Design Strategy: Social Innovation in Brazil”, Design Management Journal, Vol. 6 No. 1, pp. 40-51.

Clark, K. and Smith, R. (2010), "Unleashing the power of design thinking”, Design Management Review, Vol. 19 No. 3, pp. 8-15.

Cooper, R., Junginger, S. and Lockwood, T. (2009), "Design thinking and design management: A research and practice perspective", Design Management Review, Vol. 20 No. 2, pp. 46-55.

Dew, N. (2007), "Abduction: a pre-condition for the intelligent design of strategy", Journal of Business Strategy, Vol. 28 No. 4, pp. 38-45.

D'Ippolito, B. (2014), "The importance of design for firms' competitiveness: A review of the literature", Technovation, Vol. 34 No. 11, pp. 716-730.

Drews, C. (2009), "Unleashing the full potential of design thinking as a business method", Design Management Review, Vol. 20 No. 3, pp. 38-44.

Dunne, D. and Martin, R. (2006), "Design thinking and how it will change management education: An interview and discussion", Academy of Management Learning \& Education, Vol. 5 No. 4, pp. 512-523.

Eybers, S. and Giannakopoulos, A. (2015), "Identifying Critical Success Factors for Business Intelligence Systems", in The European Conference on Information Systems Management, Academic Conferences International Limited, p. 77.

Fraser, H. (2009), "Designing business: New models for success", Design Management Review, Vol. 20 No. 2, pp. $56-65$.

Gloppen, J. (2009), "Perspectives on Design Leadership and Design Thinking and How They Relate to European Service Industries", Design Management Journal - Des Manag J, Vol. 4, pp. 33-47.

Hassi, L. and Laakso, M. (2011), Conceptions of design thinking in the management discourse. In European Academy of Design Biannual Conference, Porto, Portugal.

Holloway, M. (2009), "How tangible is your strategy? How design thinking can turn your strategy into reality", Journal of Business Strategy, Vol. 30 No. 2/3, pp. 50-56. 
Kimbell, L. (2009), "Beyond design thinking: Design-as-practice and designs-in-practice”, in CRESC Conference, Manchester.

Liedtka, J. (2011), "Learning to use design thinking tools for successful innovation", Strategy \& Leadership, Vol. 39 No. 5, pp. 13-19.

Liedtka, J. (2015), "Perspective: Linking design thinking with innovation outcomes through cognitive bias reduction", Journal of Product Innovation Management, Vol. 32 No. 6, pp. 925-938.

Liedtka, J., King, A. and Bennett, K. (2013), Solving Problems with Design Thinking: Ten Stories of What Works, Columbia University Press.

Lockwood, T. (2009), “Transition: How to Become a More Design-Minded Organization”, Design Management Review, Vol. 20 No. 3, pp. 28-37.

Martin, R. (2010), "Design thinking: achieving insights via the "knowledge funnel”, Strategy \& Leadership, Vol. 38 No. 2, pp. $37-41$.

Martin, R.L. (2009), The Design of Business: Why Design Thinking Is the next Competitive Advantage, Harvard Business Press.

Micheli, P., Jaina, J., Goffin, K., Lemke, F. and Verganti, R. (2012), "Perceptions of Industrial Design: The "Means" and the "Ends": Perceptions of Industrial Design", Journal of Product Innovation Management, Vol. 29 No. 5, pp. 687-704.

Perks, H., Cooper, R. and Jones, C. (2005), "Characterizing the Role of Design in New Product Development: An Empirically Derived Taxonomy*”, Journal of Product Innovation Management, Vol. 22 No. 2, pp. 111-127.

Porcini, M. (2009), "Your New Design Process Is Not Enough—Hire Design Thinkers!", Design Management Review, Vol. 20 No. 3, pp. 6-18.

Rauth, I., Carlgren, L. and Elmquist, M. (2014), "Making it happen: Legitimizing design thinking in large organizations". Design Management Journal, Vol. 9 No. 1, pp. 47-60.

Rosensweig, R.R. (2011), "More than Heroics: Building Design as a Dynamic Capability: Design as a Dynamic Capability", Design Management Journal, Vol. 6 No. 1, pp. 16-26.

Rylander, A. (2009), "Design thinking as knowledge work: Epistemological foundations and practical implications", Design Management Journal, Vol. 4 No. 1, pp. 7-19.

Sato, S., Lucente, S., Meyer, D. and Mrazek, D. (2010), "Design Thinking to Make Organization Change and Development More Responsive”, Design Management Review, Vol. 21 No. 2, pp. 44-52.

Seidel, V.P. and Fixson, S.K. (2013), “Adopting design thinking in novice multidisciplinary teams: The application and limits of design methods and reflexive practices", Journal of Product Innovation Management, Vol. 30 No. S1, pp. 19-33.

Stickdorn, M., Schneider, J., Andrews, K. and Lawrence, A. (2011), This is service design thinking: Basics, tools, cases (Vol. 1). Hoboken, NJ: Wiley.

Thorpe, R., Holt, R., Macpherson, A. and Pittaway, L. (2005), "Using knowledge within small and medium-sized firms: A systematic review of the evidence", International Journal of Management Reviews, Vol. 7 No. 4 , pp. 257-281.

Ward, A., Runcie, E. and Morris, L. (2009), "Embedding innovation: design thinking for small enterprises", Journal of Business Strategy, Vol. 30 No. 2/3, pp. 78-84.

Wölbling, A., Krämer, K., Buss, C.N., Dribbisch, K., LoBue, P. and Taherivand, A. (2012), “Design Thinking: An Innovative Concept for Developing User-Centered Software", in Software for People, Springer Berlin Heidelberg, pp. 121-136. 